\title{
ANÁLISE DO POTENCIAL EÓLICO NA REGIÃo METROPOLITANA DE NATAL - RN
}

\author{
Allan Rodrigues Silva ${ }^{1, *}$, Ana Carla dos Santos Gomes ${ }^{1}$, Micejane da Silva Costa ${ }^{1}$, Maytê \\ Duarte Leal Coutinho ${ }^{1}$, Thalyta Soares dos Santos ${ }^{1}$ \\ ${ }^{1}$ Universidade Federal do Rio Grande do Norte - UFRN, Natal - RN, Brasil \\ *allansilva.r@gmail.com
}

\section{RESUMO}

Este trabalho teve como objetivo fazer uma análise do potencial eólico na região metropolitana de Natal no Estado do Rio Grande do Norte, obtendo assim a característica do vento e potência de geração de energia eólica utilizando a distribuição de weibull.

\begin{abstract}
This work aimed to make a wind potential analysis in the metropolitan region of Natal in the State of Rio Grande do Norte, thus obtaining the characteristic of wind power and wind power generation using the weibull distribution.
\end{abstract}

\section{INTRODUÇÃO}

Nos dias atuais, a necessidade suprir a demanda mundial de energia fez surgir um maior interesse pelo desenvolvimento de fontes alternativas de energia. Destacando a energia eólica que, em 2013, fez o país se posicionar entre os 10 países com maior capacidade eólica instalada no mundo (EPE, 2013), em especial, a região Nordeste do Brasil, podendo ser uma das mais privilegiadas do mundo em recursos eólicos.

Este trabalho tem como objetivo analisar os recursos eólicos na região metropolitana de Natal - RN.

\section{DADOS E METODOLOGIA}

Os dados utilizados foram do projeto "LAVAT - Laboratório de Variáveis Tropicais", no período de janeiro a dezembro de 2011. A estação dispõe de equipamentos de aquisição de dados, modelo CR10X (Campbell Scientific Inc. - USA), sensores de velocidade e direção Young (Marine Model), gerando o conjunto de dados com resolução temporal de 01 minuto. Utilizou a distribuição probabilidade de Weibull, que assume uma relação entre a distribuição da velocidade do vento e a potência, sendo definida pela Equação (1), sugerida por Sansigolo (2005).

$$
f_{v}=\frac{k}{A}\left(\frac{v}{A}\right)^{(k-1)} \cdot e^{-\left(\frac{v}{A}\right)^{k}}
$$

Para o cálculo de Energia Anual Gerada - EAG, foi calculada utilizando a Equação (2), proposta por CUSTODIO, 2009. 


$$
E A G=\sum\left[f_{v} \cdot P_{v}\right] * 8760[k W h]
$$

\section{RESULTADOS E DISCUSSÕES}

A Figura 1 apresenta a distribuição de velocidade dos ventos anual, no período chuvoso e seco. E suas variáveis como: velocidade média do vento $(\mathrm{U})$ e densidade de potência $(\mathrm{P})$, bem como os valores do fator de forma (k) e escala (A). É possível notar baixa intensidade da velocidade do vento anual, o que pode ser explicado pela atuação das brisas terrestre resultado este também encontrado por SILVA (2009) e SANTOS (2008), estudando o regime de vento no litoral alagoano.

Nota-se que, de maneira geral, as variáveis U, k e A registraram os maiores valores durante o período seco, e apresentaram ainda uma menor variabilidade da direção do vento com predominância de mais $60 \%$ de sudeste. Já durante o período chuvoso os observa uma maior variação da direção do vento em comparação ao período seco, dividida em dois quadrantes (sul/sudeste), e ventos menos intensos. Isto representa um fator negativo, pois, segundo CRESESB (2010), quanto maior a variação da direção do vento maior será a complexidade para a instalação de mecanismos para manter o eixo perpendicular ao escoamento onde influência a força de sustentação e/ou arrasto, ocasionando o giro dos rotores responsáveis pela geração de energia elétrica.

Foi feita uma estimativa da energia anual produzida, foi selecionada a turbina eólica VESTAS V82 $(1650 / 900 \mathrm{~kW})$ de $1650 \mathrm{~kW}$ de potência nominal como modelo, velocidade de cut-in e cut-out de $3 \mathrm{~m} / \mathrm{s}$ e $20 \mathrm{~m} / \mathrm{s}$ respectivamente, altura do Hub (cubo) 70 metros e diâmetro do rotor de 82 metros. Os resultados obtidos da EAG foi 1,5 GW/h ano.

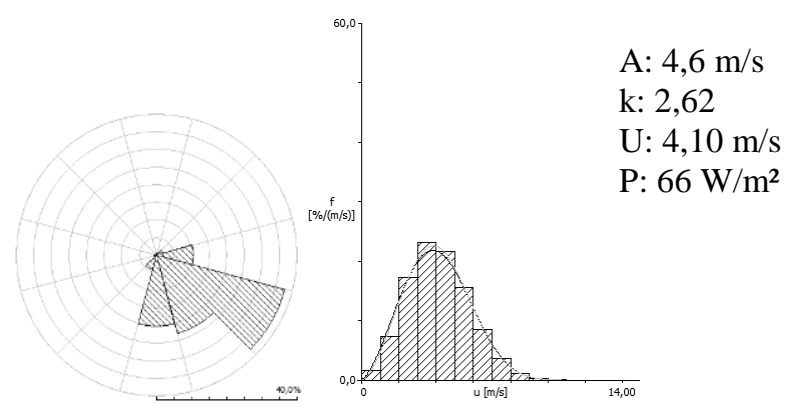

(a)

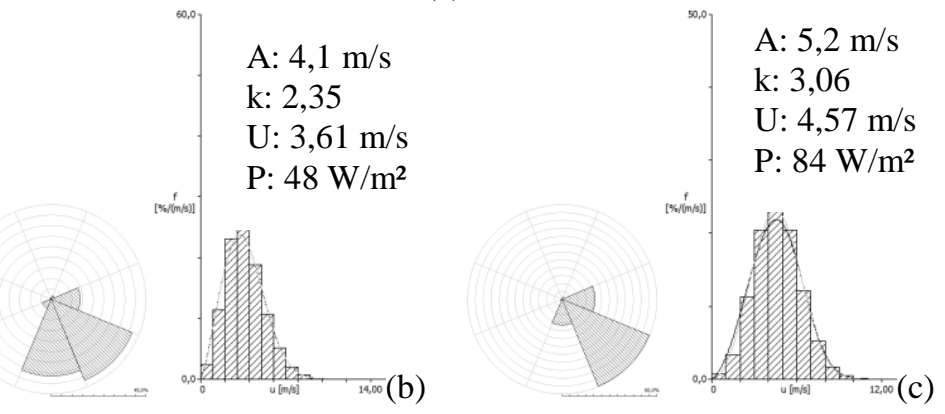

Figura 1 - Distribuição da estatística do vento a 50m, anual (a), Chuvoso (b) e Seco (c). 


\section{CONCLUSÃO}

Os resultados mostraram valores satisfatórios da velocidade do vento para região. Destaca-se os períodos chuvoso e seco que os parâmetros da função Weibull obtiveram melhores no período seco, bem como uma menor variabilidade de direção do vento.

A capacidade teórica EAG do sistema eólico de referência apontaram uma capacidade de geração para a média do município pesquisado de 1,5 $\mathrm{GWh}$ anualmente para cada $\mathrm{m}^{2}$ de área aproveitada.

\section{REFERÊNCIAS}

Centro de Referência para a Energia Solar e Eólica Sérgio de Salvo Brito: CRESESB. Disponível em: <www.cresesb.cepel.br>. Acesso em: 22 abr. 2010.

Brasil. Empresa de Pesquisa Energética. Balanço Energético Nacional 2013 - Ano base 2012: Relatório Síntese, Rio de Janeiro: EPE, 55 p., 2013.

SANSIGOLO, C. A. Distribuições de Probabilidade de velocidade e potência do vento. Revista Brasileira de Meteorologia, v20, n2, 207-214, 2005.

SANTOS, T. S. Distribuição da Precipitação e Suas Interações com os Sistemas de Brisas em um Ecossistema de Manguezal em Alagoas. Trabalho de Conclusão de Curso em Meteorologia. Instituto de Ciências Atmosféricas, Universidade Federal de Alagoas, Maceió, 60f., 2008.

SILVA, A. R. Estudo Observacional do Regime do Vento no Estado de Alagoas, nos Períodos Seco e de Transição Seco-Chuvoso. Trabalho de Conclusão de Curso em Meteorologia. Instituto de Ciências Atmosféricas, Universidade Federal de Alagoas, Maceió, Alagoas, Brasil 64p. Fevereiro de 2009. 